\title{
Consumers' delayed consumption of bakery products: Effect on physical and chemical properties
}

Nurfatimah Mohd Thania, *Siti Mazlina Mustapa Kamala, Alifdalino Sulaimana, Farah Saleena Taipa, Rozita Omarb

${ }^{a}$ Department of Process and Food Engineering, Faculty of Engineering, Universiti Putra Malaysia, 43400, Serdang, Selangor, Malaysia

${ }^{b}$ Department of Chemical and Environmental Engineering, Faculty of Engineering, Universiti Putra Malaysia, 43400, Serdang, Selangor, Malaysia.

\section{ARTICLE HISTORY}

Received: 7 April 2020

Received in revised form: 30 April

2020

Accepted: 1 May 2020

Available Online: 4 May 2020

\section{Keywords}

Bakery products

Food wastes

Physical properties

Chemical properties

\section{Abstract}

Delay in the consumption of bakery products has contributed to the food waste problem which is a serious global issue. Delayed consumption or can be regarded as the 'leftovers' bakery products such as croissants and doughnuts are normally discarded due to the impairment in texture or quality degradation causing them to taste not as good as fresh baked, although the products still edible. Thus, this study aims to evaluate the physical and chemical changes during the delaying of consumption of croissants and doughnuts at three (3) different storage times (day 0,1 and 2). The hardness of croissants and doughnuts had an increased throughout storage time, with doughnuts have the higher hardness than croissants, with $175.63 \%$ and $92.31 \%$ increased, respectively. Carbohydrate was found as the major component for croissants and doughnuts. Croissants and doughnuts recorded carbohydrate content of (50.32-52.42\%) and (43.22-46.59\%), respectively, from day 0 to day 2 . While sugar profile analysis detected three types of monosaccharides sugars, which were fructose, glucose and maltose for croissants and doughnuts. Thus, high content of carbohydrate and monosaccharides that available in the leftovers doughnut and croissants suggest that it could potentially be used as renewable resources for sugar recovery.

\section{Introduction}

According to Melikoglu \& Webb, (2013) and Taylor (2012), every year around the world, 1.2 million tonnes of bread in various forms have been discarded. Unfortunately, $80 \%$ of the total wasted bread was still edible and disposed even before their expiry date, or even worst have been mistakenly believed as spoil and later were thrown away.

Due to short shelf life, bakery product has major changes in physiochemical characteristics during its storage that effect on aroma, taste, and texture (Haroon et al., 2016; Alibardi and Cossu, 2016). The accumulation of these bakery waste can lead to greenhouse gas (GHG) emission as their degradation is biological. This large quantity of bakery waste affects natural resources in terms of the nutrients, water, soil, and energy disruption of biogenic cycles.

Bakery waste can be generated at different levels of the supply chain as explained by (Joshi \& Sharma, et al. 2011). It initially started from the raw materials where it is discarded as waste if it is unusable or delayed in processing and if the quality is not on par with the standard requirement. Even if the products were produced, but if it does not match the company standards or spoil during storage, marketing, and transportation, it will also be discarded as waste. While in the production or manufacturing stage; equipment inefficiency, spillage or improper handling, can also generate waste. Lastly, some quantity of the product is also wasted at consumers' end due to improper use or delay in consumption. Even though consumers were in the last tier, the waste can be generated due to several factors, such as indecisive purchasing, storage conditions, over preparations and uncertainty of shelf-life's term (Papargyropoulou et al., 2015). Besides that, other reasons were the bread is out of date, looked bad, plate leftover, in fridge/cupboard too long, cooked leftover, freezer burn and went mouldy (Taylor , 2012).
Bakery leftovers often happen at consumers' end due to improper use or delay in consumption. Bakery leftovers are also generated mostly at bakeries, where most of the bakery products are discarded even it is still edible. This is a common practice at the bakery in order to provide only fresh products daily.

One of the methods in managing bakery leftovers is utilizing and converting it into other valuable products. Bakery leftovers are very rich in carbohydrates in its formulation, mostly derived from the wheat flour. Carbohydrate is a compound that classified into monosaccharides, oligosaccharides, and polysaccharides depending on their molecular weight or degree of polymerisation and also digestible as well as non-digestible property. It is a complex compound with the formula $\mathrm{C}_{n}\left(\mathrm{H}_{2} \mathrm{O}\right)_{n}$ and can be broken down into smaller monomers of sugar (monosaccharides or disaccharides) which can later be used in other applications. Thus, sugar can be recovered from bakery leftover through the hydrolysis of carbohydrates.

However, due to the various type of scenarios and also source of which bakery leftovers could be generated, it is crucial to know the effect of these variables on the physical and chemical changes of bakery leftovers. Minimal changes in chemical composition (especially in carbohydrate content) over time will prove that bakery leftovers hold great potential as renewable resources for sugar production. Hence, this study will imitate one of the common scenarios that have contributed to the bakery leftovers issue, which was delaying the consumption of bakery products by consumers, and later discarded it even if it is still edible. The study aims to evaluate any changes in terms of physical and chemical compositions of bakery products throughout time.

\section{Materials and methods}

\subsection{Preparation of sample}


In this study, two different types of bakery products were being selected, which were croissants (Figure 1) and doughnuts (Figure 2) that were collected from two different local bakery shops in Selangor, Malaysia.

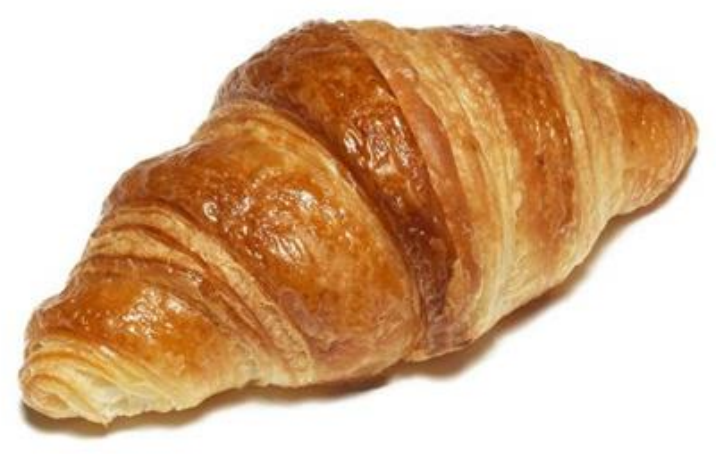

Figure 1. Croissant

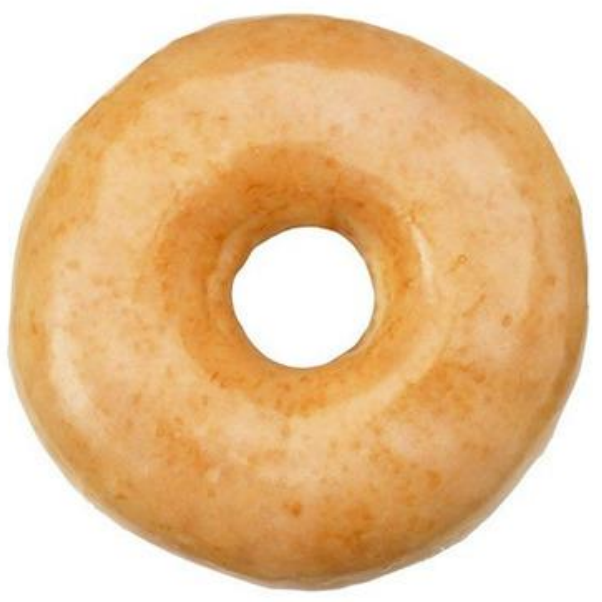

Figure 2. Ring-shape doughnut

They were kept in an airtight, see-through plastic container at room temperature for a maximum of 2 days ( 48 hours) after freshly baked. Three stages of storage time were chosen for the samples to be analyzed; day 0 (freshly baked), day 1 ( 24 hours after baked) and day 2 (48 hours after baked). The maximum time frame of 2 days was chosen based on the report by Revell \& Revell, (2019). The report comprises the information on food storage from multiple research conducted by the U.S. government agencies, which stated that freshly baked croissant can last 1-2 days (room temperature), 5-7 days (refrigerator) and 1-2 months (freezer); while freshly baked doughnut can last 1-2 days (room temperature), 1 week (refrigerator) and 2-3 months (freezer).

Yeast and mold analyses that were carried out on day 1 and day 2, have shown that both croissant and doughnut were in the acceptable limit, which was $5 \times 10^{3} \mathrm{CFU} / \mathrm{g}$ as mentioned by Hozová, et al., (2002), where doughnut remained $<100 \mathrm{CFU} / \mathrm{g}$ for day 1 and day 2. Meanwhile, croissant reported $<100 \mathrm{CFU} / \mathrm{g}$ for day 1, but slightly increased on day 2 (150 CFU/g). Nevertheless, the results were still within the safe limit, therefore croissant and doughnut were considered to be in good and safe to consume condition. The croissants and doughnuts were now recognised to be leftovers croissant (LC) and leftover doughnut (LD).

\subsection{Texture analysis}

TA.XT2 texture analyser (Stable Micro System) was used for texture analysis. The instrument was fitted with a probe set up to record the force used to penetrate the sample. Each bakery used different probe, where LC used knife edge and LD used 75 $\mathrm{mm}$ cylinder probe. The selection of the test method and probe was based on "BAKERY PRODUCT Test Method" that is originally built into Exponent Texture Analyzer software. The textural data (force versus time) was analysed by the software to determine the hardness of the samples.

\subsection{Proximate analysis}

Proximate analysis was performed for LC and LD based on the AOAC method (A.O.A.C., 2000). Carbohydrate was determined from the difference of moisture, ash, protein and fat content. Moisture content was determined after oven drying at $105{ }^{\circ} \mathrm{C}$ for $8 \mathrm{~h}$, while ash content was carried out using a dry ashing method. The Kjeldahl method was applied to determine protein content with a conversion factor of 6.25 , and finally, fat content was carried out by soxhlet extraction (FOSS SoxtecTM 2050).

\subsection{Sugar profile analysis}

Quantification and determination of the type of sugars in LC and LD were performed via high-performance liquid chromatography (HPLC) (Jasco, Japan) according to AOAC 16th Ed: 977.20 sugar separation method. The type of column used was Grace-Davison Prevail CarbohydrateES $5 \mu(150 \mathrm{~mm}$ x 4.6 $\mathrm{mm}$ ). $75 \%: 25 \%$ acetonitrile and ultrapure water were used as the mobile phase, and the sample was injected at a flow rate of $0.9 \mathrm{~mL} / \mathrm{min}$. The standard curves of glucose, fructose, mannose, galactose, and arabinose were prepared for reference. The yield of monosaccharide was calculated using Equation 1.

Yield of monosaccharides (mg/g substrate)

$$
=\frac{\mathrm{M}_{\text {mono }}(\mathrm{mg} / \mathrm{L}) \times \mathrm{V}_{\mathrm{aq}}(\mathrm{L})}{\mathrm{W}_{\text {substrate }}(\mathrm{g})}
$$

Where,

$\mathrm{M}_{\text {mono: }}$ Concentration of monosaccharides

$\mathrm{V}_{\mathrm{aq}}$ : Volume of aqueous phase

$\mathrm{W}_{\text {substrate: }}$ Mass of substrate

\subsection{Statistical analysis}

A two-way factorial for statistical analysis was carried out using the Design of Expert (DOE), with a confidence limit of 95 $\%$. All the data were presented in mean \pm standard deviation.

\section{Results and discussion}

\subsection{Texture analysis}

Texture is an important element for baked products as the consumers prioritize physical conditions (appearance and texture) before consuming them. In this study, hardness was selected as the primary parameter for the texture analysis, as croissant and doughnut are easily affected by the moisture from the environment. Hardness can be defined mechanically and sensory, as a force necessary to attain a given information on the 
texture as well as force required to compress a substance between molar teeth or between tongue and palate (Szczesniak, 2002). Figure 3 exhibits the hardness trend of bakery products against storage time. All bakery products increased in hardness from day 0 to day 2 .

Texture of bakery products was hugely affected by moisture from the environment as starch was the major component in the formulations. The modifications in the bakery products related to starch behavior can be correlated to starch gelatinization and retrogradation. This phenomenon also known as the disorganization of the order of starch granules, swelling and rupture of the granules, and reorganization of the disordered molecules (Matignon \& Tecante, 2017). Starch retrogradation often leads to deterioration of food product quality, mainly involving bread staling and aging of starch-containing desserts (Berski, et al., 2018).

Overall, doughnuts (from producer 2) have the highest hardness difference of $175.63 \%$ (from day 0 to day 2) while croissants (from producer 2) have the least difference with only $92.31 \%$. The physical nature of croissants which renders to be less dense than doughnuts due to the laminating stage during baking may have contributed to croissants having lower hardness as compared to doughnuts. Furthermore, another factor that might affect the hardness is moisture. Gray and BeMiller (2003) explained that in freshly baked croissants and doughnuts, there is a high moisture content on the inside and low moisture content on the outside. During storage, water migration happened from the inside to outer crust and later diffuses to the environment which has less moisture. Previous researchers have reported that the bread crumb firming during storage also attributed due to starch to starch and gluten to starch interactions (Goesaert et al., 2005, Goesaert et al., 2008).
Similarly, croissants and doughnuts which were also formulated with starch (wheat flour), strengthen their starch-starch and gluten-starch interactions due to water loss during storage. Thus, this condition allows the products to harden as compared to the initial condition.

\subsection{Proximate analysis}

Proximate analysis was conducted in order to determine the changes in chemical composition at different storage times. Table 1 shows the percentage of compositions of protein, moisture, ash, fat and carbohydrate of croissants and doughnuts. There were minimal changes in chemical compositions detected during storage. Both croissants and doughnuts have shown high content of carbohydrate from Day 0 to Day 2; 43.22-46.59\% and 50.32-52.42\%, respectively. This is expected since the major component in the formulation of bakery products is starch (compounds of carbohydrate) that originated from wheat flour.

From Table 1, the second major component was moisture, $27.49-24.63 \%$ from day 0 to day 2 for croissant, and 28.82$26.29 \%$ for doughnut. Moisture is easily affected because of starch in its formulation. The difference in moisture gradient (inside of croissant and doughnut as well as in the environment) has resulted in the loss of moisture from the bakery products into the environment. Croissant has higher initial moisture (day 0) due to its hollow physical structure resulted from laminating steps in its cooking preparation. Fat was the third major component in croissant and doughnut, originating from butter during dough preparation. Doughnuts recorded higher fat content (17.70-17.64\% from day 0 to day 2), while croissant $10.64-10.77 \%$ from day 0 to day 2 . The higher fat content in doughnut may be resulted from the cooking method, where

a)

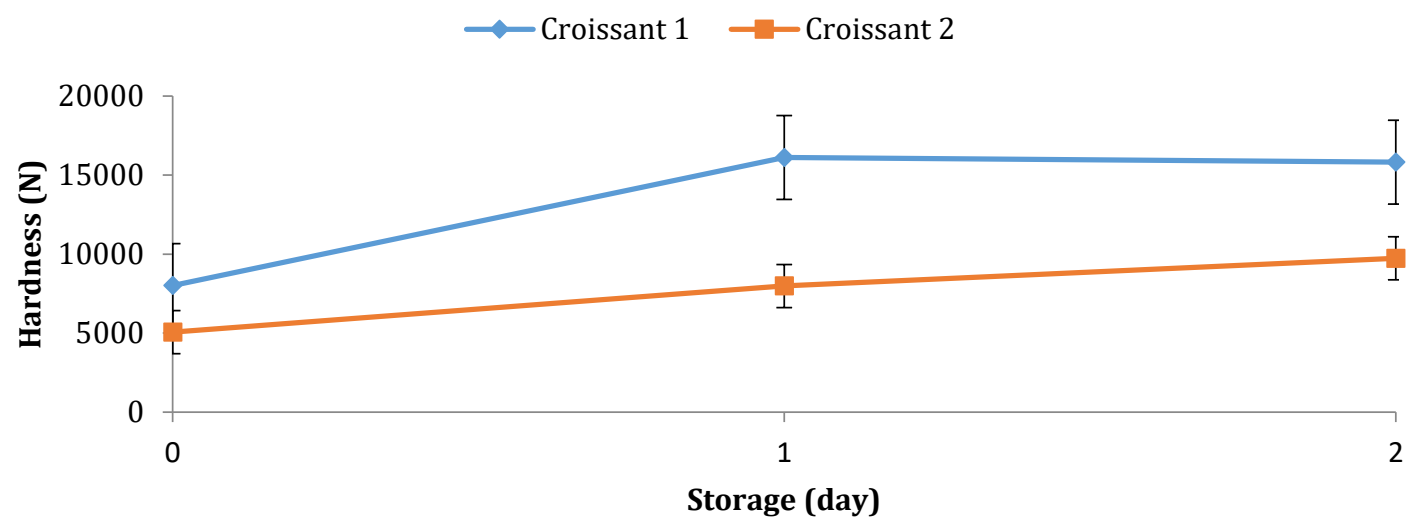

b)

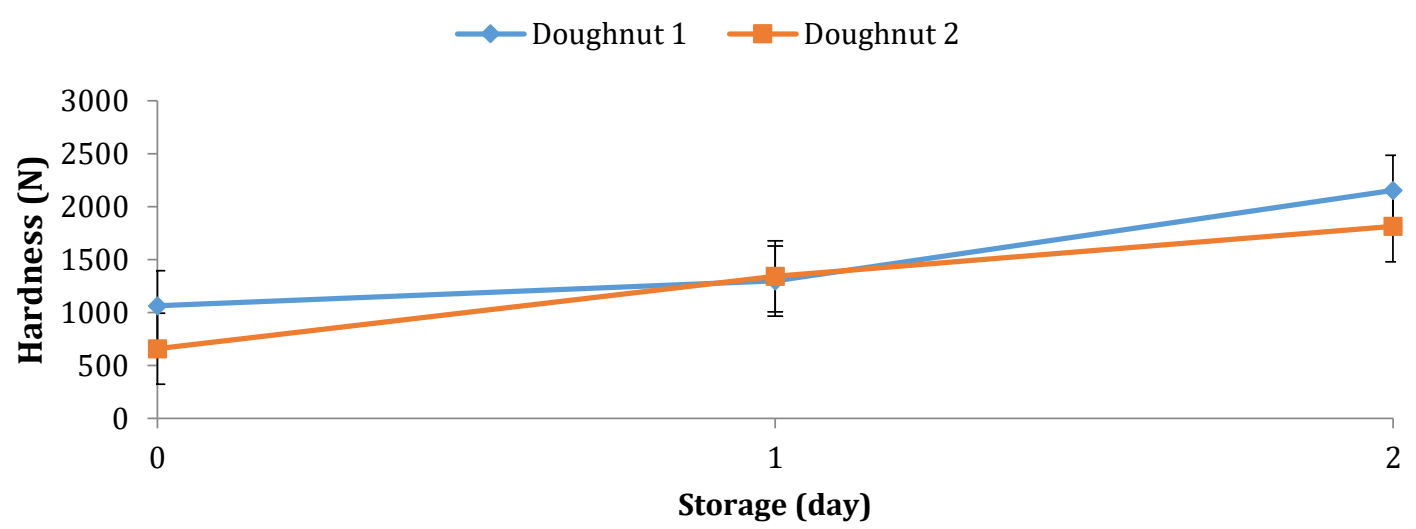

Figure 3. Hardness of different bakery products (a) croissants (b) doughnuts, throughout storage time 
Table 1. Proximate analysis of croissant and doughnut from different bakery shop, at various storage time

\begin{tabular}{|c|c|c|c|c|c|c|}
\hline \multirow[b]{2}{*}{ Bakery Products } & \multirow[b]{2}{*}{ Day } & \multicolumn{4}{|c|}{ Components (\%) } & \multirow[b]{2}{*}{ Carbohydrate } \\
\hline & & Protein & Moisture & Ash & Fat & \\
\hline \multirow[t]{3}{*}{ Croissant 1} & 0 & $8.98 \pm 0.25$ & $31.2 \pm 0.98$ & $1.00 \pm 0.16$ & $10.67 \pm 0.72$ & $48.16 \pm 0.19$ \\
\hline & 1 & $9.31 \pm 0.44$ & $35.82 \pm 0.91$ & $1.00 \pm 0.03$ & $10.34 \pm 0.89$ & $43.54 \pm 0.03$ \\
\hline & 2 & $8.83 \pm 0.11$ & $26.52 \pm 1.02$ & $1.49 \pm 0.68$ & $10.57 \pm 0.85$ & $52.21 \pm 0.27$ \\
\hline \multirow[t]{3}{*}{ Croissant 2} & 0 & $9.47 \pm 0.79$ & $26.44 \pm 0.47$ & $0.99 \pm 0.08$ & $10.62 \pm 0.33$ & $52.49 \pm 0.93$ \\
\hline & 1 & $9.02 \pm 0.38$ & $27.89 \pm 0.92$ & $1.48 \pm 0.35$ & $10.23 \pm 0.71$ & $51.39 \pm 0.88$ \\
\hline & 2 & $9.22 \pm 0.14$ & $26.05 \pm 0.98$ & $1.50 \pm 1.06$ & $10.98 \pm 0.33$ & $52.62 \pm 0.18$ \\
\hline \multirow[t]{3}{*}{ Doughnut 1} & 0 & $10.05 \pm 0.94$ & $23.76 \pm 0.84$ & $1.49 \pm 0.07$ & $17.12 \pm 0.92$ & $47.59 \pm 0.71$ \\
\hline & 1 & $9.94 \pm 1.02$ & $25.54 \pm 0.77$ & $1.99 \pm 0.03$ & $16.18 \pm 0.44$ & $46.37 \pm 0.87$ \\
\hline & 2 & $9.57 \pm 0.54$ & $24.57 \pm 0.88$ & $0.99 \pm 0.02$ & $17.18 \pm 0.83$ & $46.75 \pm 0.19$ \\
\hline \multirow[t]{3}{*}{ Doughnut 2} & 0 & $9.65 \pm 0.38$ & $31.22 \pm 1.02$ & $2.00 \pm 0.08$ & $18.29 \pm 0.92$ & $38.85 \pm 0.82$ \\
\hline & 1 & $9.77 \pm 0.64$ & $27.26 \pm 0.75$ & $1.97 \pm 0.21$ & $17.32 \pm 0.53$ & $43.69 \pm 0.77$ \\
\hline & 2 & $9.99 \pm 0.89$ & $24.68 \pm 0.56$ & $1.75 \pm 0.39$ & $18.10 \pm 0.33$ & $46.42 \pm 0.42$ \\
\hline
\end{tabular}

doughnut requires a deep-frying process whereby the dough may absorb a certain amount of fat from the frying oil. Whereas for croissant, the fat components not only come from butter in the dough but also during the laminating process, whereby every layer would be spread with butter.

Minimal changes were observed for the composition values of protein, carbohydrate, fat, moisture content and ash throughout the storage, which indicate the values attained to be almost similar with freshly baked products (Day 0 ). On day 2 , the average percentage of each component of croissant (croissant 1 and 2) as well as doughnut (doughnut 1 and 2) were calculated. It was found that carbohydrate was slightly higher in croissants $(52.42 \pm 0.29 \%)$ than doughnuts $(46.59 \% \pm 0.23 \%)$. However, doughnuts contained a higher percentage of protein $(9.78 \pm 0.28 \%)$ and fat $(17.64 \pm 0.65 \%)$ than croissants' protein $(9.02 \pm 0.28 \%)$ and fat $(10.77 \pm 0.29 \%)$. Meanwhile, croissants showed a higher percentage of moisture $(26.29 \pm 0.33 \%)$ and ash $(1.49 \pm 0.01 \%)$ as compared with doughnuts' moisture $(24.63 \pm 0.08 \%)$ and $\operatorname{ash}(1.37 \pm 0.54 \%)$.

\subsection{Sugar profile analysis}

Sugar profile analysis was conducted in order to study the sugar alteration during storage. Figure 4 displays three types of monosaccharides detected in all bakery products, which were fructose, glucose and maltose. Fructose is the major monosaccharide for croissants and doughnuts. Croissants recorded an average of 2.66-2.28 g/100 g fructose, 1.36-1.19 $\mathrm{g} / 100 \mathrm{~g}$ glucose and $0.50-0.48 \mathrm{~g} / 100 \mathrm{~g}$ maltose (from day 0 to day 2). Meanwhile, doughnuts have an average of 0.88-0.90 $\mathrm{g} / 100 \mathrm{~g}$ fructose, $0.47-0.49 \mathrm{~g} / 100 \mathrm{~g}$ glucose and $0.45-0.58 \mathrm{~g} / 100$ $\mathrm{g}$ maltose (from day 0 to day 2).

Fructose and glucose were derivations of sucrose, a disaccharide that is commonly found in sugar, which is one of the materials used in the formulation of croissants and doughnuts. Fructose and glucose were linked via a glycosidic bond. Whilst maltose, also known as maltobiose or malt sugar is a disaccharide formed from two units of glucose, connected by $\alpha(1 \rightarrow 4)$ bond. The presence of maltose in croissants and doughnuts can be traced to the flour that was used in the formulations, which originated from wheat.

\section{Conclusion}

Different bakery products have different formulations and cooking methods that influence physical and chemical compositions. It was found that physical properties, especially the hardness of croissant and doughnut were affected during storage. Doughnuts have a higher hardness increment of 175.63 $\%$ (from day 0 to day 2) compared to croissants. From the proximate analysis, carbohydrate is the major component of croissants and doughnuts, and it was increased from day 0 to day 2; 43.22-46.59 \% and 50.32-52.42 \%, respectively. However, chemical compositions of croissants and doughnuts have minimal changes over time. This finding is beneficial as it indicates that the leftovers croissants and doughnuts still retained its chemical composition throughout storage. The finding also implied that, even in the form of leftovers, waste or rejected products, the chemical compositions (especially carbohydrate) within croissants and doughnuts, were almost as similar as freshly baked. Although there have been changes in the physical properties of croissants and doughnuts, the chemical compositions matter more, which it potentially be used for sugar recovery. These conditions have made leftovers croissants and doughnuts as a potential renewable resource that the carbohydrate in the leftovers can be utilized and converted into other functional products.

\section{Author contributions}

Nurfatimah Mohd Thani designed and executed the experimental and the conceptual framework, analyzed the data, and wrote the manuscript. Siti Mazlina Mustapa Kamal, Alifdalino Sulaiman, Farah Saleena Taip and Rozita Omar supervised the project and findings as well as verified all the analytical methods.

\section{Conflict of interest}

The authors declare that they have no known competing financial interest or any conflict of interest that could influence the work reported in this paper.

\section{Acknowledgments}

This study was supported by the Geran Putra IPS (Vote no. 9573200) from the Universiti Putra Malaysia. 
a)

\section{Croissant}

Fructose Glucose Maltose

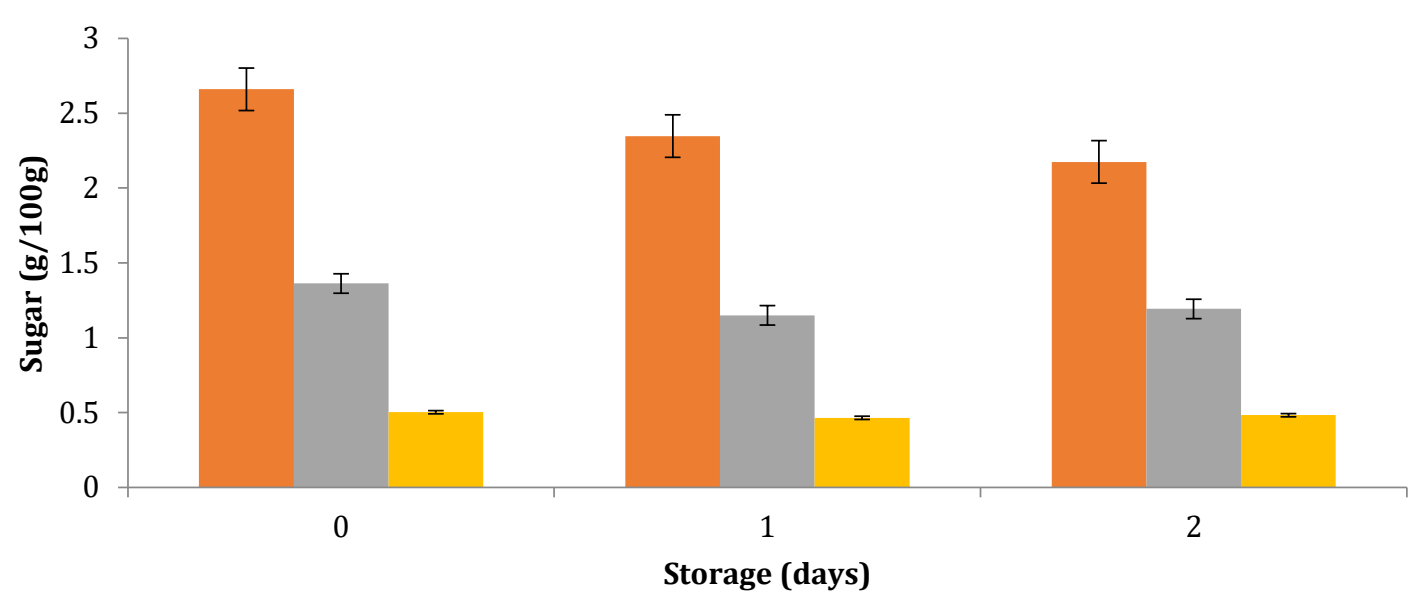

b)

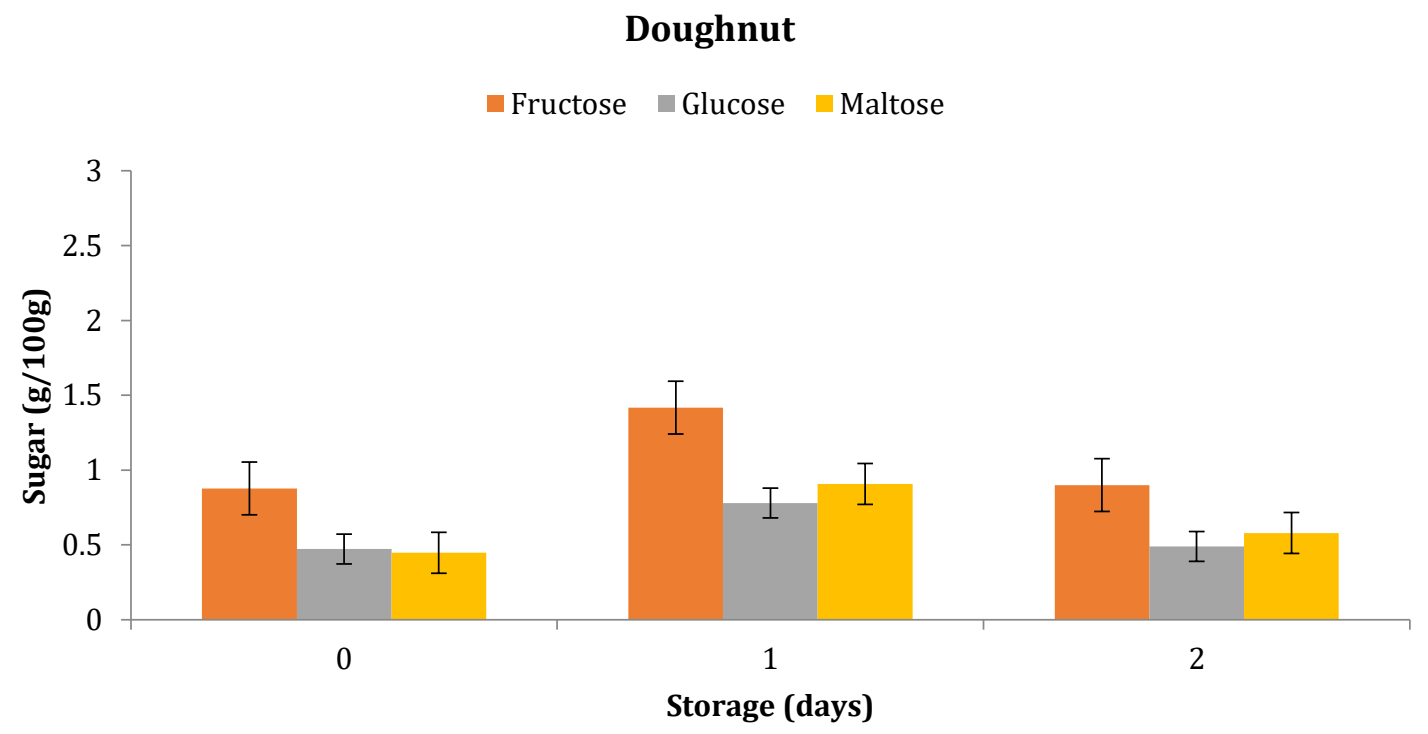

Figure 4. Sugars detected in (a) croissant and (b) doughnut 


\section{References}

Alibardi, L., \& Cossu, R. (2016). Effects of carbohydrate, protein and lipid content of organic waste on hydrogen production and fermentation products. Waste management 69-77. https://doi.org/10.1016/j.wasman.2015.07.049

A.O.A.C. (2000). Official Methods of Analysis of AOAC International, 17th Edition. Maryland: AOAC International.

Cauvin, S., \& Young, L. (2006). Baked products: science, technology and practice. Blackwell Publishing.

Gray, J., \& Bemiller, J. (2003). Bread staling: molecular basis and control. Comprehensive reviews in food science and food safety , 2 (1), 1-21. https://doi.org/10.1111/j.15414337.2003.tb00011.x

Goesaert, H., Brijs, K., Veraverbeke, W.S., Courtin, C.M., Gebruers, K., Delcour, J.A., (2005). Wheat flour constituents: how they impact bread quality, and how to impact their functionality. Trends Food Sci.Technol. 16 (1), 12-30.

Goesaert, H., Leman, P., Delcour, J.A., (2008). Model approach to starch functionality in bread making. J. Agric. Food Chem. 56 (15), 6423-6431.

Haroon, S., Vinthan, A., Negron, L., Das, S., \& Berenjian, A. (2016). Biotechnological approaches for production of high value compounds from bread waste. American Journal of Biochemistry and Biotechnology , 12, 102-109. 10.3844/ajbbsp.2016.102.109

Hartley, A. (2019). A brief history of the croissant. Retrieved from Alto.Hartley: https://altohartley.com/a-brief-historyof-the-croissant/

Hozová, B., Turicova, R., \& Lenkeyova, I. (2002). Microbiological and sensory quality and stored croissant-type bakery products depending on external (sorbic acid) and internal (dough, aw value) conditions. Nahrung , 46 (3), 144-150. https://doi.org/10.1002/15213803(20020501)46:3\%3C144::AIDFOOD144\%3E3.0.CO;2-X

Melikoglu, M., Lin, C., \& Webb, C. (2013). Stepwise optimisation of enzyme production in solid state fermentation of waste bread pieces. Food and Bioproducts Processing, 91, 638-646. https://doi.org/10.1016/j.fbp.2013.04.008

Moncel, B. (2019). The history of doughnuts. Retrieved from The spruce eats: https://www.thespruceeats.com/thehistory-of-doughnuts-1328766

Revell, J., \& Revell, R. (2019). Food storage- How long can you keep. Retrieved from Still Tasty: Your ultimate shelf life guide: https://www.stilltasty.com/Fooditems/index/17109

Szczesniak, A. (2002). Texture is a sensory property. Food Quality and Preference , 13, 215-225. https://doi.org/10.1016/S0950-3293(01)00039-8

Tako, M., Tamaki, Y., Teruya, T., \& Takeda, Y. (2014). The principles of starch gelatinization and retrogadation. Food and Nutrition Sciences , 5, 280-291. http://dx.doi.org/10.4236/fns.2014.53035

Taylor, A.-L. (2012). BBC Food. BBC News. 